\title{
The development and characteristics of a hand-held high power diode laser-based industrial tile grout removal and single-stage sealing system
}

\author{
J. Lawrence*, K. Minami**, M.J.J. Schmidt**, L. Li**, R.E. Edwards*** and A.W. Gale*** \\ *Manufacturing Engineering Division, School of Mechanical \& Production Engineering, Nanyang \\ Technological University (NTU), Nanyang Avenue, Singapore 639798. \\ **Laser Processing Research Centre, Manufacturing Division, Department of Mechanical
}

Engineering, University of Manchester Institute of Science and Technology (UMIST), Manchester, M60 1QD, UK.

***Department of Civil and Construction Engineering, University of Manchester Institute of Science and Technology (UMIST), Manchester, M60 1QD, UK.

\section{Correspondence}

Dr. Jonathan Lawrence,

Manufacturing Engineering Division,

School of Mechanical \& Production Engineering,

Nanyang Technological University (NTU),

Nanyang Avenue,

Singapore 639798.

Tel : (65) 67905542

Fax : (65) 67911859

email : mjlawrence@ntu.edu.sg 


\section{ABSTRACT}

As the field of laser materials processing becomes ever more diverse, the high power diode laser (HPDL) is now being regarded by many as the most applicable tool. The commercialisation of an industrial epoxy grout removal and single-stage ceramic tile grout sealing process is examined through the development of a hand-held HPDL device in this work. Further, an appraisal of the potential hazards associated with the use of the HPDL in an industrial environment and the solutions implemented to ensure that the system complies with the relevant safety standards are given. The paper describes the characteristics and feasibility of the industrial epoxy grout removal process. A minimum power density of approximately $3 \mathrm{~kW} / \mathrm{cm}^{2}$ was found to exist, whilst the minimum interaction time, below which there was no removal of epoxy tile grout, was found to be approximately $0.5 \mathrm{~s}$. The maximum theoretical removal rate that may be achievable was calculated as being $65.98 \mathrm{~mm}^{2} / \mathrm{s}$ for a circular $2 \mathrm{~mm}$ diameter beam with a power density of $3 \mathrm{~kW} / \mathrm{cm}^{2}$ and a traverse speed of $42 \mathrm{~mm} / \mathrm{s}$. In addition, the characteristics of the single-stage ceramic tile grout sealing are outlined. The single-stage ceramic tile grout sealing process yielded crack and porosity free seals which were produced in normal atmospheric conditions. Tiles were successfully sealed with power densities as low as $550 \mathrm{~W} / \mathrm{cm}^{2}$ and at rates of up to $420 \mathrm{~mm} / \mathrm{min}$. In terms of mechanical, physical and chemical characteristics, the single-stage ceramic tile grout was found to be far superior to the conventional epoxy tile grout and, in many instances, matched and occasionally surpassed that of the ceramic tiles themselves.

Key words: High power diode laser (HPDL); Ceramic tiles; Grout; Removal; Enamel; Glaze; Beam delivery; Safety 


\section{INTRODUCTION}

When it comes to new and diverse applications, the high power diode laser (HPDL) is increasingly being recognised by many as the most suitable laser. This is largely due to the unique application flexibility and the inherent advantageous operating characteristics of the HPDL. Consequently, the HPDL is rapidly becoming the tool of choice for many engineering tasks. Notwithstanding the growing popularity of the HPDL, its use, and that of other lasers for that matter, within the field of civil engineering is very limited. However, recent studies indicate that high power lasers have a strong potential for replacing many existing methods within the industry [1-3]. Using $\mathrm{CO}_{2}$ lasers the cutting of marble has been studied by Pires et al. [4] and Kumer et al. [5], whilst the cutting of concrete and reinforced concrete within the nuclear industry has been carried out by Sugita et al. [6] and Yoshizawa et al. [7]. Also, as part of nuclear plant decommissioning, Li et al. [8-11] conducted research to determine the workability of several laser techniques for sealing/fixing radioactive contamination onto concrete surfaces. In a similar study, Blair [12] experimented with techniques such as the direct glazing of the concrete and single and multiple layer fusion cladding. For purely aesthetic purposes, Sugimoto et al. [13] examined the modification of the surface appearance and surface properties of cement based materials using a $\mathrm{CO}_{2}$ laser, the resultant physical characteristics and mechanical behaviour of the post-process cement based materials were later fully characterised by Wignarajah et al. [14]. Similarly, Borodina et al. [15] analysed the structural changes within the composition of zirconia concrete caused by surface exposure to $\mathrm{CO}_{2}$ laser radiation. Extensive studies by Lawrence and Li [16-19] investigated the treatment of the OPC surface of concrete with both $\mathrm{CO}_{2}$ and HPDL's. The work revealed that the HPDL generated OPC glazes were more than an effective surface modification insofar as it provided superior mechanical, physical and chemical characteristics over an untreated or $\mathrm{CO}_{2}$ laser treated OPC surface.

Owing mainly to the outstanding functional characteristics of glazed ceramic tiles, their use within civil engineering remains extensive. Generally, glazed ceramic tiles are applied to walls using tile grout, which is typically epoxy based. But the lifespan of the epoxy grout is much shorter than that of the tiles themselves because contaminants can enter into, and exit a space via a tiled surface, through the tile grouts used to fill the void between adjoining tiles [20]. In addition, commercially available tile grouts are extremely difficult to clean and over time they consequently become contaminated and have to be removed physically or mechanically. In view of these inherent problems, however, only a moderate amount of research has been conducted in an attempt to ameliorate these attendant problems. Even fewer studies have been carried out to investigate the possibility of using lasers to provide a solution. Lawrence et al. [21-23] have exclusively pioneered the use of the high power diode laser (HPDL) to devise a two- stage ceramic tile grout sealing process. The process uses a new grout material which comprises of two distinct components: an amalgamated oxide compound grout 
(AOCG) substrate and a glazed enamel surface. The HPDL two-stage ceramic tile grout sealing technique was shown to yield crack and porosity free seals. An examination of the mechanical, chemical and physical characteristics of the seals showed that the generation of the enamel surface glaze resulted in a seal with improved mechanical and chemical properties over those of conventional epoxy tile grouts.

Most epoxy grouts consist of polymeric or hydraulically bounded materials [22]. Through heating of the epoxy grout with a high power laser under certain conditions, water evaporation, material expansion and decomposition of organic compounds will occur within the beam interaction zone of the material. This in turn produces internal stresses and pressure within the material which consequently lead to its removal $[13,24]$. Indeed, the laser cleaning processes describe by Cooper [24, 25], Lazzarini et al. [26] and Asmus et al. [27] share very similar characteristics to the HPDL epoxy grout removal process. Furthermore, according to Ready [28], any laser-based removal process is akin to the laser cutting of non-metallic materials. Johnston et al. [29] have reported on the successful removal of the surface layer of concrete (scabbling) by means of $\mathrm{Nd}: \mathrm{YAG}$ and $\mathrm{CO}_{2}$ laser radiation. Moreover, Morishita et al. [30] has identified two removal processes that are in action during laser removal (up to the depth of $10 \mu \mathrm{m}$ ), namely evaporation and melting. In a similar manner, Schmidt et al. [31] investigated a HPDL-based paint stripping process for the removal of layers (up to $0.35 \mathrm{~mm}$ ) of paint (chlorinated rubber) coated onto concrete. This work concluded that the process was the result of laser induced and sustained combustion when an $\mathrm{O}_{2}$ processing gas was employed.

This work describes the development of a hand-held HPDL system that can both remove an industrial epoxy grout and then seal ceramic tiles by means of a single-stage ceramic tile grout seal. It is believed that the development of this system will go some way to help fully commercialise the process. In addition, an appraisal of the potential hazards associated with the use of the HPDL in an industrial environment and the solutions implemented to ensure that the system complies with the relevant safety standards are given.

\section{EXPERIMENTAL PROCEDURES}

\section{A. Materials preparation and application}

For both industrial epoxy grout removal and the single-stage sealing of ceramic tiles, UK standard $150 \times 150 \times 5 \mathrm{~mm}^{3}$ vitrified ceramic tiles were used. The tiles were cut into smaller pieces, $20 \mathrm{x}$ $20 \mathrm{~mm}^{2}$, for experimental purposes and applied in pairs to an OPC substrate using the industrial epoxy tile grout (Vallance Ltd). The spacing between the vitrified edges of each tile pair was the 
industry recommended $1.5 \mathrm{~mm}$. The fixed ceramic tile pieces were then allowed to set for the standard setting time of $24 \mathrm{~h}$.

For the removal experiments the void between adjoining ceramic tiles was filled with the epoxy grout and allowed to dry for the recommended $48 \mathrm{~h}$. To ensure that accurate results were obtained the surface of the grout was smooth, clean and levelled. The epoxy grout used consists of acrylic emulsion, limestone (filler), dolomite (filler) and a cellulose substance (thickener).

For the sealing experiments, vitrified ceramic tiles were crushed and fine ground using a pestle and mortar and then sieved to ensure a particle size of less than $30 \mu \mathrm{m}$. So as to form a manageable paste, the vitrified ceramic tile powder was mixed with approximately $50 \mathrm{wt} \%$ water diluted sodium silicate solution. The vitrified ceramic tile paste was then placed into the void, flush to the surface of the tiles and allowed to cure for $8 \mathrm{~h}$. The set mixture was then overlaid directly with a thin layer $(500 \mu \mathrm{m})$ of enamel frit which, in order to form a manageable paste, was mixed with $20 \mathrm{wt} \%$ white spirit. The composition of the enamel consisted mainly of the following: $\mathrm{SiO}_{2} ; \mathrm{B}_{2} \mathrm{O}_{3} ; \mathrm{Na}_{2} \mathrm{O} ; \mathrm{Mn}$ and small quantities of $\mathrm{Ba} ; \mathrm{Al}_{2} \mathrm{O}_{3}$ and $\mathrm{Ni}$, whilst the powder size was less than $25 \mu \mathrm{m}$. The enamel frit paste was allowed to cure for $1 \mathrm{~h}$ whereupon it was immediately irradiated with the defocused HPDL beam.

\section{B. Laser processing arrangement}

A surgical HPDL (Diomed Ltd.) was employed for the industrial epoxy grout removal and singlestage ceramic tile grout sealing work. The laser emitted at $810 \mathrm{~nm} \pm 20 \mathrm{~nm}$ and operating in the CW mode with rated optical powers ranging from 0-60 W. The HPDL beam was delivered to the work area by means of a $4 \mathrm{~m}$ long, $600 \mu \mathrm{m}$ core diameter optical fibre, the end of which was connected to a 2:1 focusing lens assembly mounted on the z-axis of a 3-axis CNC gantry table. The samples were irradiated using the defocused high order mode HPDL beam with a beam spot diameter of $1.75 \mathrm{~mm}$ and HPDL powers (measured at the workpiece after fibre and optics losses using a Power Wizard power meter) of 10-45 W. The defocused HPDL beam was fired across the surface of the samples by traversing the samples beneath the HPDL beam using the $\mathrm{x}$ - and $\mathrm{y}$-axis of the CNC gantry table at various traverse speeds. To study the possible effects of different process gasses on the removal process, compressed air, $\mathrm{Ar}, \mathrm{N}_{2}$ and $\mathrm{O}_{2}$ was blown coaxially. Based on previous work by Lawrence $e t$ al. [21, 22], only coaxially blown $\mathrm{O}_{2}$ process gas was used in the sealing study. The fumes produced were removed with an extraction system. In order to analyse the HPDL treated specimens, they were sectioned with a Struers cutting machine using a diamond rimed cutting blade and then polished using cloths and diamond suspension pastes. The sectioned samples were then examined using optical microscopy, scanning electron microscopy (SEM), energy dispersive X-ray (EDX) and X-ray diffraction (XRD) techniques. 


\section{INDUSTRIAL EPOXY GROUT REMOVAL PROCESS}

\section{A. Laser processing parameter characteristics}

\section{Effects of process gas type}

Studies of the effects of different process gases during the laser processing of materials have hitherto been concentrated on the laser welding and cutting of steels and the laser ablation drilling and surface treatment of other metals. These studies have revealed the high degree of influence that the process gas employed has on the process [32-34]. In particular, a comprehensive investigation by Low et al. [34] revealed that, whereas the use of an $\mathrm{O}_{2}$ process gas typically caused increased liquid particle ejection coupled with volatile burning, the use of an Ar process gas induced material ejection predominantly by bulk radial liquid ejection.

The epoxy grout removal rate using compressed air, $\mathrm{Ar}, \mathrm{N}_{2}$ and $\mathrm{O}_{2}$ process gases in terms of HPDL power density and traverse speed are given in Fig. 1 and Fig. 2 respectively. As is evident from Fig. 1 , the relationship between the epoxy grout removal rate and the HPDL power density was found to be linear, with greater removal being occasioned with increases in the power density. However, as Fig. 2 shows, the grout removal rate remained consistent within a small traverse speed range. Such a finding implies that traverse speed has very little effect on the removal rate. It is clear from Fig. 1 and Fig. 2 that a greater removal rate was occasioned by employing $\mathrm{O}_{2}$ as the process gas. It is postulated that this occurrence is due to the natural high reactivity of $\mathrm{O}_{2}$ relative to the other three process gases. As one can see from Fig. 1 and Fig. 2, Ar, compressed air and $\mathrm{N}_{2}$ exhibited similar results to one another in terms of the grout removal rate.

\section{Effects of laser operating characteristics}

A schematic illustration of the operating window for the HPDL removal of the epoxy grout using $\mathrm{O}_{2}$ is given in Fig. 3. Within the optimum operating conditions the effective removal of the epoxy grout was possible. From the operating window it is possible to determine the maximum theoretical removal rate that may be achievable using the HPDL. This was calculated as being $65.98 \mathrm{~mm}^{2} / \mathrm{s}$ for a circular $2 \mathrm{~mm}$ diameter beam with a power density of $3 \mathrm{~kW} / \mathrm{cm}^{2}$ and a traverse speed of $42 \mathrm{~mm} / \mathrm{s}$.

As one can see from Fig. 3, the HPDL power density required to effect satisfactory removal increased with an increase in traverse speed. The curve, however, can be divided into three separate regions in which distinctive removal characteristics can be discerned. First, in Region I the gradient of the curve gradually reduces as the traverse speed approaches $20 \mathrm{~mm} / \mathrm{s}$, but increases exponentially from $25 \mathrm{~mm} / \mathrm{s}$ in Region III. Between a traverse speed of 15 and $25 \mathrm{~mm} / \mathrm{s}$ (Region II), a linear relationship between the power density and the traverse speed exists, indicating that optimum process controllability may be obtained by employing these operating parameters. This implies that the 
process becomes inefficient when the traverse speed is increased to more than $25 \mathrm{~mm} / \mathrm{s}$ and the power density is beyond $2 \mathrm{~kW} / \mathrm{cm}^{2}$. This state of affairs may be explained by the fact that debris in the form of removed epoxy grout was observed to remain within the laser interaction area after processing. It is suspected that this debris acted as a block to both the process gas and the HPDL beam, thereby causing a reduction in both the cooling rate and the reaction rate. This in turn would result in inefficient epoxy grout removal and heat accumulation within the material. It is also evident from Fig. 3 that a minimum power density threshold of $300 \mathrm{~W} / \mathrm{cm}^{2}$ exists, below which removal will not occur regardless of the traverse speed. Further, a minimum interaction time of approximately $0.5 \mathrm{~s}$ for the effective removal of the epoxy grout was found to exists.

\section{B. Morphology, microstructure and phase characteristics}

The majority of the debris observed after HPDL interaction with the epoxy grout generally took the form of ash, being a mixture of grey and white in colour with small, darker areas around the interaction zone. This darker debris is probably the 'coke' produced by the burning of the material with insufficient $\mathrm{O}_{2}$ supply. The degree of heat affected zone (HAZ) occasioned as a result of HPDL interaction was determined with a phenolphthalein indicator. The HAZ was found around the laser interaction region as well as within the laser track region. This spreading of the HAZ beyond the laser track region when using an $\mathrm{O}_{2}$ process gas was probably due to the high rate of temperature elevation within the material during HPDL interaction.

Typical SEM images of the surface of the removed epoxy grout are shown in Fig. 4. It is apparent from Fig. 4 that modifications to the microstructure of the epoxy grout were brought about as a result of HPDL interaction. The surface of the HPDL treated samples exhibited a collection of segments and grouped particles with gaps, whereas the untreated samples displayed a continuous monostructured plane surface. This may be due to the high reactivity of $\mathrm{O}_{2}$ giving rise to a higher surface temperature, which in turn caused dehydration, melting and re-solidification of certain substances comprising the epoxy grout during HPDL processing

In the XRD plots given in Fig. 5, crystal structural changes within the material resulting from HPDL interaction can be discerned. $\mathrm{CaCO}_{3}, \mathrm{CaO}$ and $\mathrm{CaMg}\left(\mathrm{CO}_{3}\right)_{2}$ were found to be the primary compounds after HPDL interaction (Fig. 5(b)). The formulation of these compounds is considered to be the product of the decomposition of $\mathrm{CaCO}_{3}$ (limestone) (Fig. 5(a)). Additionally, as can be seen from Fig. 5(a), $\mathrm{SiO}_{2}$ that existed in the untreated epoxy grout material was not detected after HPDL interaction, as it is evident from Fig. 5(b). It is believed that the failure to detect any trace of $\mathrm{SiO}_{2}$ in the epoxy grout after HPDL interaction is due to the compound vitrifying. 


\section{Thermal history during high power diode laser processing}

In order to predict the reactions taking place within the epoxy grout sample during HPDL interaction, and thus determine the thermal history of the epoxy grout during HPDL processing, a thermogravimetric-differential thermal analysis (TG-DTA) was carried out (Fig. 6). A drop in weight and a minor exothermic reaction were seen at approximately $200^{\circ} \mathrm{C}(\mathrm{A})$. This indicates that the first reaction within the material is likely to be the evaporation of moisture and solvent. At approximately $300-400^{\circ} \mathrm{C}(\mathrm{B})$, the second reaction was noted by the occurrence of an $\mathrm{O}_{2}$ induction period. This was then followed by a strong exothermic reaction within the material. A small trough and the rapid increase in the DTA signify such events in the material [35]. Approximately $8 \%$ of the total weight loss is also experienced by the epoxy grout during this period. The degradation of the polymer was thought to be the cause of these events. The polymer in the epoxy grout is a polyacrylate or poly (methyl methacrylate), which is widely used as a reactive adhesive [36]. The third reaction commences with dehydration, decomposition and expansion of the cementing material at approximately between $400-575^{\circ} \mathrm{C}(\mathrm{C})$, in which a steady endothermic reaction and a small weight loss were seen. Naturally, it is expected that these alternations made to the epoxy grout will reduce the strength of the material. At $575^{\circ} \mathrm{C}$, transformation of $\alpha$ (low) to $\beta$ (high) quartz (i.e. crystal structure change) was believed to happen. This supposition was verified somewhat when a modification to $\mathrm{SiO}_{2}$ was observed during the XRD analysis. After this stage $\left(600-800^{\circ} \mathrm{C}\right)$ (D), a continuous decrease in DTA and a significant weight loss are detected. Decarbonation of $\mathrm{CaCO}_{3}$ is an endothermic reaction [37], which results in $\mathrm{CaOH}$ and $\mathrm{CO}_{2}$. Evolving $\mathrm{CO}_{2}$ gas is marked by the weight loss and a large peak in the DTA at approximately $750^{\circ} \mathrm{C}(\mathrm{E})$. This suggests that such an incident resulted in the development of heat from the material. At above $600^{\circ} \mathrm{C}$ the material experiences serious break down and the material surface become porous. Transformation of $\alpha \mathrm{Fe}_{2} \mathrm{O}_{3}$ into $\beta \mathrm{Fe}_{2} \mathrm{O}_{3}$ at $662^{\circ} \mathrm{C}(\mathrm{F})$, and $\beta$ (high) quarts to $\beta 2$ tridymite at $870^{\circ} \mathrm{C}(\mathrm{G})$ was also supposed to happen with further heating [40]. As for the last stage of the reaction at above $1000^{\circ} \mathrm{C}$, decomposition and fusion of other compounds progresses, such as $\mathrm{SiO}_{2}\left(\mathrm{~T}_{\mathrm{m}}=1050^{\circ} \mathrm{C}\right)$, are caused.

\section{SINGLE-STAGE CERAMIC TILE GROUT SEALING}

\section{A. Effect of laser operating parameters}

The single-stage ceramic tile grout seal was found to successfully seal ceramic tiles with power densities as low as $550 \mathrm{~W} / \mathrm{cm}^{2}$ and at rates of up to $420 \mathrm{~mm} / \mathrm{min}$. Fig. 7 shows a schematic representation of the operating window for the single-stage ceramic tile sealing process. Within the optimum operating conditions, good quality surface glazes displaying neither microcracks nor porosities could be generated. Moreover, these glazes could be generated without the need for special 
atmospheric conditions. A typical example of a glaze generated within these laser operating parameters is shown in Fig. 8.

Variations in the laser power density were seen to have a significant effect upon the surface morphology of the enamel glazes, as one can see from Fig. 9. A minimum power density level of around $1 \mathrm{~kW} / \mathrm{cm}^{2}$ was observed, below which incomplete glazing of the enamel occurred, regardless of the traverse speed. HPDL interaction at this level resulted in a seal which appeared only partially vitrified. At a relatively medium power density $\left(2 \mathrm{~kW} / \mathrm{cm}^{2}\right)$, however, the quality of the enamel surface glaze on the enamel was much improved. Here complete vitrification of the enamel occurred, with the surface displaying very few microcracks and no porosities. When glazing with a relatively high power density $\left(3 \mathrm{~kW} / \mathrm{cm}^{2}\right)$, the quality of the enamel surface glaze was extremely poor, displaying many large microcracks and porosities.

As with power density variations, Fig. 10 shows clearly that changes to the traverse speed had a significant effect upon the surface morphology of the enamel glaze. From the experiments it was observed that at relatively low $(<120 \mathrm{~mm} / \mathrm{min})$ and high $(>480 \mathrm{~mm} / \mathrm{min})$ traverse speeds, the surface condition of the enamel glazes were unacceptable. In such instances the glazed surfaces displayed many large porosities and microcracks. At medium traverse speeds in the range of $180-420 \mathrm{~mm} / \mathrm{min}$, however, good quality surface glazes on the enamel could be generated which displayed neither porosities nor microcracks.

\section{B. Glazing/melting characteristics}

Exposure of the crushed ceramic tile mix to rapid heating as a result of HPDL vitrification of the enamel frit results in further densification of the upper section of the crushed ceramic tile mix. This essentially entails the removal of the pores between the starting particles of the mix, combined with growth together and strong bonding between adjacent particles [38]. A microscopic cross-sectional examination of the single-stage seal revealed that the crushed ceramic tile mix possessed an upper densified layer, with a gradual decrease in the amount of densification as the depth increases. In addition, an XRD analysis of the crushed ceramic tile mix after HPDL vitrification of the enamel frit revealed that the structure was mainly polycrystalline in nature, with only partial vitrification taking place. This indicates that the densification of the upper sections of the crushed ceramic tile mix is achieved primarily by solid-state material transport, driven by differences in free-energy or chemical potential [38]. However, the fact that partial vitrification of upper section of the crushed ceramic tile mix was observed suggests that the formation of a liquid glass phase was induced, which is often the case with ceramic materials [38].

As mentioned previously, within the optimum operating parameters, the HPDL fired enamel glazes on the surface of the single-stage tile grout seals generally displayed neither porosities nor 
microcracks. The fact that such surfaces displaying almost no porosities can be created is primarily due to the nature of the optimum single-stage ceramic tile grout's composition which resulted in the optimum single-stage ceramic tile grout having a reasonable propensity to laser treatment. This is due in particular to the presence within the optimum single-stage ceramic tile grout composition of $\mathrm{Zn}$, which is known to impart fluidity in to the molten optimum single-stage ceramic tile grout during laser treatment by reducing the viscosity $[39,40]$. Thus the surface of the solidified optimum singlestage ceramic tile grout is porosity free, since during cooling any generated gases could escape more freely into the atmosphere from the molten optimum single-stage ceramic tile grout $[39,40]$. The avoidance of microcracking in the HPDL generated enamel glaze is due to relatively low the value of the thermal gradient, $\Delta \mathrm{T}$, induced in the enamel during HPDL irradiation. This is due partly to the fact that the softening point of the enamel powder is around $500^{\circ} \mathrm{C}$, hence the tensile stresses that result from the unrelieved elastic stresses that occur due to the contraction of the material between the softening point $\left(500^{\circ} \mathrm{C}\right)$ and ambient temperature $\left(20^{\circ} \mathrm{C}\right)$ are reduced to a value well below that of the fracture strength of the enamel. Consequently cracking will not occur, thus rendering any pre- or post-heating of the enamel completely unnecessary

\section{Bonding characteristics}

An analysis of the bond region between the HPDL generated enamel glaze and the crushed ceramic tile mix revealed that there was no dendritic growth in bond region. This is somewhat surprising as the presence of dendrites is a characteristic of enamels fired onto substrates which, like the crushed ceramic tile mix, contain $\mathrm{Fe}, \mathrm{Si}$ and in particular, $\mathrm{Co}$ [42]. However, an interface region in which some of the base crushed ceramic tile mix had dissolved into the enamel was observed. Indeed, an EDX analysis of the bond region between the enamel seal and the crushed ceramic tile mix revealed that within this interface region, elements unique to both components of the single-stage ceramic tile grout seal were present. Greenhut asserts that complex combinations of the various bonding mechanisms actually come into play according to the types of materials used [42]. For the crushed ceramic tile mix and the enamel, the mechanisms involved in ceramic-glass bonding are reasonably applicable. These principally include: physical bonding (van der Waals forces), chemical bonding (oxide transformation and $\mathrm{O}_{2}$ bridging) and on a very small scale, electrochemical reactions such as the electrolytic effect (redox reaction) due to the presence of ferric oxides within the crushed ceramic tile mix reacting with other oxides in the enamel [42]. But in the case of the crushed ceramic tile mix and the enamel, the predominant bonding mechanism results from physical forces, since adhesion between many materials is assured by electron transfer and is, therefore, related to bandgap energy [43]. Thus for non-conducting materials, such as the crushed ceramic tile mix, with large bandgaps, there will be practically no free charges inside the ceramic crystals, even at elevated temperatures. In 
this case the electron transfer at the interface will not take place since the electron transfer depends exclusively on the concentration of free charges in the ceramic crystal [43]. As a result, the chemical contribution to the work of adhesion is negligible [43]. Nevertheless, the bonding mechanism between the HPDL treated crushed ceramic tile mix and the enamel may not be entirely due to physical forces owing to the fact that enamel glazes on ceramic materials such as the crushed ceramic tile mix are typically bonded as a result of some of the base material dissolving into the glaze [43]. Indeed, it is well known that $\mathrm{Na}^{+}$is extremely mobile and can, therefore, diffuse to create an interfacial zone of intermediate composition. However, such an interfacial zone was not observed during a cross-sectional analysis of the bond region.

\section{Mechanical, chemical and physical characteristics of the single-stage ceramic tile grout seal}

The British and international standards in place at present regarding tile grout are concerned only with water absorption and compressive strength. For ceramic tiles, standard tests exist for the determination of water absorption and chemical resistance. Consequently it was not possible to test the single-stage ceramic tile grout seals in strict accordance with established tests. So, wherever possible, tests based on current standards were developed to investigate specific aspects of particular relevance to the HPDL generated seals, namely the pull-off strength, the surface roughness, the rupture/impact strength, the wear resistance, the permeability characteristics (water) and the corrosion resistance. Details of these actual tests can be found elsewhere [23]

Marked variations in the results with changes in the HPDL operating parameters were observed. Yet little variation within the optimum laser operating parameters was observed, thus implying that neither the power density nor the traverse speed influenced the bond strength of the enamel glaze. The average strength of the bond between the enamel glaze and the crushed ceramic tile mix was recorded as $79 \mathrm{MPa}$, whilst the strength of the bond between the enamel glaze and the borosilicate glass surface of the ceramic tiles was found to be $52 \mathrm{MPa}$. A post-test analysis of the samples showed that in both cases, bond failure occurred at the interface between the enamel glaze and the materials. Further, an optical analysis of the detached surfaces showed that the enamel had detached cleanly and completely from the crushed ceramic tile mix and the borosilicate glass surface of the ceramic tiles.

Arguably one of the most important features of the single-stage ceramic tile grout seal is the surface roughness of the enamel glaze itself, for it is this that determines the cleanability of the tiled surface as a whole. Using the Taylor-Hobson Surtonic 3+ surface texture measuring instrument, a series of measurements were taken on the surface of a layer of an epoxy grout (polished to ensure a measurement could be taken), the vitrified surface of a ceramic tile and the surface of the enamel glaze. On each sample, four measurements were taken in different positions and in different 
directions on the surface, with an average being taken. Table 1 summarises the surface roughness (Ra) measurement results. As is evident from Table 1, the surface roughness of the enamel seal is many times less than that of a conventional epoxy grout, even when polished. In ordinary operating conditions where the surface roughness of the epoxy grout is not polished, but is determined by the means of application, the surface roughness was measured to be in excess of $30 \mu \mathrm{m}$. Clearly, in this situation the surface roughness, and hence the cleanability, of the single-stage ceramic tile grout seal will be considerably better.

Tests were conducted to determine the rupture strength of the enamel glaze when comprising a complete single-stage ceramic tile grout seal and the vitreous glaze on the surface of a ceramic tile. The results of the experiments revealed that there was little variation between the average rupture strength of the enamel seal and the vitreous tile glaze, $2.8 \mathrm{~J}$ and $3.0 \mathrm{~J}$, with the enamel seal ranging from 2.5-3.0 J, whilst the vitreous tile glaze ranged from only 2.9-3.0 J. It is interesting to note that because of the shape of the tile edges, the enamel glaze when HPDL fired naturally assumes a concave surface geometry. As such, the strains within the enamel layer are higher, therefore reducing the strength (if the enamel glaze assumed a flat surface profile) by some 40-50\% [45]. Additionally, it is well established that substrate thickness has a significant effect upon the rupture strength of an enamel coating [45]. As such, because the thickness of the single-stage ceramic tile grout seal as a whole was not controlled as accurately as the thickness of the bulk ceramic tile material, then slight variations in the recorded rupture strength are perhaps to be expected.

The wear resistance of a material is generally determined by the hardness of the material in comparison with the hardness of other materials with which it comes into contact [46]. Hence the greater hardness of the compositional components of the enamel glaze on the single-stage ceramic tile grout (principally $\mathrm{SiO}_{2}, \mathrm{~B}_{2} \mathrm{O}_{3}, \mathrm{Na}_{2} \mathrm{O}$ and $\mathrm{Mn}$ ) in comparison with the epoxy tile grout (principally $\mathrm{CaCO}_{3}$ and dolomite) probably results in improved wear resistance. However, wear resistance does not always increase with hardness [46]. Tests were therefore to determine the exact difference in wear resistance between the conventional epoxy tile grout and the glazed enamel surface of the single-stage ceramic tile grout. Here, all the samples were weighed and then clamped individually in the vice of a common shaping machine. A steel abrader was attached to the floating head of the shaping machine and moved cyclically back and forth across the surfaces of the grout seals. The total distance moved in one cycle was $6 \mathrm{~mm}$ while the traverse speed was $180 \mathrm{~mm} / \mathrm{min}$. By applying weights to the floating head a frictional force of $60 \mathrm{~N}$ was generated. The samples were subjected to the frictional force for $8 \mathrm{~h}$, being removed from the machine and weighed at $2 \mathrm{~h}$ intervals. The wear tests were repeated twice so as to give more reliable results. The standard deviation due to experimental error, etc. was calculated as being $\pm 15 \mathrm{mg}$. The wear resistance of the glazed enamel 
seal was found to be considerably greater than the epoxy tile grout, with the weight loss being 9 times lower than for the epoxy tile grout after $4 \mathrm{~h}$, and 14 times lower after $8 \mathrm{~h}$.

Perhaps the most important function of the single-stage ceramic tile grout is its propensity for preventing harmful agents from permeating through it. In order to test the permeability of the singlestage ceramic tile grout seal, in particular the glazed enamel surface, comparison experiments with conventional epoxy tile grout were conducted in terms of water permeability. The tests were based on BS 6906 [47]. From the tests it was found that the conventional epoxy tile grout had an average water permeability of approximately $4.18 \times 10^{-3} \mathrm{mg} / \mathrm{h} . \mathrm{cm}^{2}$, whilst the single-stage ceramic tile grout seal exhibited no measurable permeability. Such a result confirms that not only is the enamel seal fully amorphous, but that since there are no cracks or porosities in the enamel glaze or the interface between the enamel glaze and the borosilicate glass tile surface, it is reasonable to assume that a continuous impervious surface has therefore been created across the surface of the tiles and the seal.

Tiled surfaces are often subjected to corrosive substances, either as part of the normal service environment and/or as a result of routine cleaning. Consequently, corrosion resistance tests based upon BS 6431 [48] were conducted using nitric acid $\left(\mathrm{HNO}_{3}\right)$, sodium hydroxide $(\mathrm{NaOH})$ and a detergent cleaner (MP9, Premier Products). The experiments were carried out by dropping small amounts of the corrosive agents in the concentration ratios of $80 \%, 60 \%, 40 \%, 20 \%$ and $10 \%$ on to the surface of the epoxy tile grout and the glazed enamel surface of the single-stage tile grout at hourly intervals for $4 \mathrm{~h}$. The samples were then examined optically and mechanically tested in terms of compressive strength and wear. High concentrations of the various corrosive agents were used principally to accelerate the tests. However, in practice $60 \% \mathrm{HNO}_{3}$ is used within the nuclear processing industry as a solvent for nuclear fuels [49], whilst within the food processing and brewing industries, tiled surfaces are washed repeatedly many times a day with detergent cleaners [50]. All three substances in the concentrations $80 \%, 60 \%$ and $40 \%$ were seen to immediately attack the epoxy tile grout surface, with the $\mathrm{HNO}_{3}$ and $\mathrm{NaOH}$ attacking with greater severity than the detergent. In contrast, the glazed enamel displayed no discernible microstructural changes or signs of devitrification due to corrosion. Tests conducted according to ASTM C579-91 [51] revealed that exposure of the epoxy tile grout to the reagents had a significant effect upon the compressive strength and the wear resistance of the epoxy grout. Exposure of the epoxy grout to $\mathrm{HNO}_{3}$ and $\mathrm{NaOH}$ in the concentrations $40-80 \%$ resulted in an average loss of compressive strength of approximately $35-71 \%$. In the case of the detergent, a significant loss in compressive strength only occurred with concentrations above $40 \%$. Here the average loss in compressive strength for concentrations in the range $60-80 \%$ was approximately $15-30 \%$. This compares with no discernible difference in either the wear resistance or the compressive strength single-stage ceramic tile grout. Likewise, the wear resistance of the epoxy grout was significantly affected, particularly through interaction with the 
$\mathrm{HNO}_{3}$ and the $\mathrm{NaOH}$. Here the weight loss was approximately 5 times higher than for the unexposed epoxy tile grout after $4 \mathrm{~h}$, and approximately 10 times higher after $8 \mathrm{~h}$ for both reagents. In the case of the detergent, the weight loss was twice as high as that recorded for the unexposed epoxy tile grout after $4 \mathrm{~h}$, and 5 times higher after $8 \mathrm{~h}$.

\section{DEVELOPMENT OF THE PORTABLE HIGH POWER DIODE LASER-BASED SINGLE-STAGE CERAMIC TILE GROUT SEALING SYSTEM}

The design requirements for the single-stage ceramic tile grout sealing system can be categorised into three different groups:

- The Process Supply System which encompasses the laser, the optics system, the gas supply and any chemicals that may be required.

- Process Control which includes the monitoring and control of the operation, any possible logging requirements, and the main safety circuit.

- The Waste Removal System involves provision for the extraction system to remove gaseous and particulate matter.

To provide the system with the asset of portability, as well as giving the system as much commercial application flexibility as possible, a system based on a hand-held device has been devised. This subsequently generates a number of prerequisite requirements which define the capabilities of the intended system. These are principally:

- Process Specifications - Scanning speeds between 100 and $600 \mathrm{~mm} / \mathrm{s}$, irradiance levels of between 1 and $3 \mathrm{~kW} / \mathrm{cm}^{2}$ and variable spot sizes between 1 and $5 \mathrm{~mm}$ diameter (expected to lie in the region of $1.5 \mathrm{~mm}$ ) in order to effect adequate epoxy grout removal and allow the generation of satisfactory glazes during sealing. Also, a flexible power delivery system is imperative, namely a fibre optic beam delivery system.

- Safety Requirements - A reasonable flow of process gas to shift any particulate matter generated,

Class 1 laser safety standard through the incorporation of interlock systems, guards etc. and filtration and gas absorption devices to be added as required

A wireframe model of the hand-held HPDL beam delivery system is shown in Fig. 11. The basic specification envelope is approximately $170 \times 130 \times 130 \mathrm{~mm}^{3}$. The main housing unit of the device is machined from a solid aluminium block, with the additional components such as the handle, screen, optics core, extraction piping, optical fibre units, etc. being manufactured individually and then attached around the main housing unit. The basic design of the main housing unit holds the optics core and nozzle along the central axis, with the tip of the nozzle being just above the intended 
interaction spot. The end of the nozzle is surrounded by a reflective dome, cut into the main block, with its centre on the interaction spot. This will ensure that any reflected radiation is returned straight back to the interaction spot, thus allowing for a more efficient process. The supply of process gas is provided through the optics core and is therefore coaxial with the laser radiation. To monitor the process and to ensure good validation of the parameters, the speed is taken on one of the interlock wheels and displayed on top of the handle. An endoscope camera in the dome allows for monitoring of the interaction zone and ensures that the operator has good control over the alignment of the beam. The lower edge of the central block is approximately $1 \mathrm{~mm}$ above the tile surface. This gap, although small, must be closed for safety reasons.

The $1 \mathrm{~mm}$ gap corresponds to a 2 degree opening angle, seen from the centre of the dome. Assuming a lambertian body as the target material, $0.06 \%$ of the reflected radiation would escape through this gap (integrated over all directions). The gap area of the sphere can be approximated at $1.9 \mathrm{~cm}^{2}$. Assuming the laser system operates at $110 \mathrm{~W}$ output power, this will result in a leakage power of $0.066 \mathrm{~W}$, and therefore in a leakage power density of $0.035 \mathrm{~W} / \mathrm{cm}^{2}$. Although this figure is very small, for safety reasons this must be blocked also. To this end, a row of carbon brushes will be attached to the edges of the main block, in effect optically sealing the interaction area and ensuring Class 1 laser operation, in conjunction with the wheel interlocks, which interrupt the laser should the system be lifted off the processing surface.

Particulate extraction resulting from the epoxy grout removal process is handled by four $10 \mathrm{~mm}$ diameter extraction pipes, which are set in even gaps around the edges of the dome. Previous designs for a paint stripping processes [52], utilising three $6 \mathrm{~mm}$ pipes have proven very successful, and the additional capacity may come in useful for grout removal applications [53]. The extraction system will remove the material through the handle into a particulate filter. Gas absorption filtration can be added when necessary. Extraction and supply of gas, command signals, as well as the laser fibre will be run through an umbilical line which enters the hand-piece through the handle. This has the added advantage of allowing for a protective sleeve around al utility lines, which can be included in the interlock chain. Any damage to this unit, and therefore potentially the fibre will prohibit the use of the laser system. Naturally, the operation switch will be configured in "hold-to-run" mode so as to avoid accidental operation.

The salient advantages of the hand-held design can be summarised as follows.

1. The device would be easy to operate.

2. The versatility of the design of the device is such that it can be used for both the removal of epoxy grout and the single-sealing of ceramic tiles. 
3. The device would be able to operate across a wide range of processing conditions, thus raising the possibility of employing the device for other tasks of a similar nature.

4. The complete design itself is very compact and would, combined with the working characteristics of the HPDL, naturally allow the whole epoxy grout removal and single-stage ceramic tile grout sealing system to be totally portable.

5. The incorporated features of the design allow for full process monitoring.

6. The incorporated safety features of the design turn the system into a Class 1 Laser system, therefore making operation as safe as possible.

\section{ASSOCIATED SAFETY ASPECTS OF THE HIGH POWER DIODE LASER- BASED SINGLE-STAGE CERAMIC TILE GROUT SEALING SYSTEM}

As specified in ISO 11553 [54], it is a requirement that no human exposure to radiation exceeding levels of Class 1 Laser, according to BS EN 608251-1 [55], is possible during production (normal or otherwise). In practice, this requires that no access to a danger zone is possible during operation. Any laser system for production use will in effect have to be a Class 1 Laser system, hence any design will have to take this issue into account. The maximum permissible exposure (MPE) is defined in BS EN 60825-1 [54] and is subject to the laser intensity, spectral distribution and temporal parameters of the radiation system, as well as the type of exposure, i.e. ocular or skin exposure. If one assumes a $10 \mathrm{~s}$ exposure time limit, then the ocular and skin exposure limits are defined as:

$$
\begin{aligned}
& \text { Ocular exposure limit }=18 \cdot t^{0.75} \cdot C_{4} C_{6}\left(\mathrm{~J} / \mathrm{m}^{2}\right) \\
& \text { Skin exposure limit }=1.1 \cdot 10^{4} \cdot t^{0.25} \cdot C_{4}\left(\mathrm{~J} / \mathrm{m}^{2}\right)
\end{aligned}
$$

where $t$ is time, $C_{4}$ is a correction factor defined as $10^{0.002 \cdot(\lambda-700)}$, which for our case (since $\lambda=810$ nm) results in $\mathrm{C}_{4}=1.659$ and $C_{6}$ can be assumed to be 1 , even if the exposure limit should be increased for diffuse viewing. So, the resulting MPE values determined with assumed exposure times of $10 \mathrm{~s}, 1 \mathrm{~s}$ and $10^{-3} \mathrm{~s}$ are given in Table 3.

The MPE equivalent power density values are relevant for exposure times from $10^{-3} \mathrm{~s}$ to $10 \mathrm{~s}$, which it is believed cover all instances of the single-stage ceramic tile grout sealing processes. Additionally, blink reflexes, as well as pain reactions can be assumed to ensure a sufficient limitation in exposure times $[56,57]$. It can be seen that the leakage power density that would be generated from the handpiece without a lower edge beam guard is some way over the MPE irradiance for ocular exposure. It should, however, be noted that the MPE calculated in this case is a worst case scenario, assuming the unlikely occurrence of $100 \%$ reflection from the interaction zone. The value also does not account for the expanded angular effects through the diffuse radiation. That is, it assumes the exposure occurs 
directly at the edge of the handpiece. It can be said with a reasonable amount of confidence that the system would adequately fulfil the requirements for a Class 1 Laser system, as long as the interlock chain ensures that there is no irradiation, if the system is not on a process surface.

\section{CONCLUSIONS}

The feasibility and characteristics of an industrial epoxy grout removal process and a single-stage ceramic tile grout sealing process have been investigated. Moreover, the commercialisation of a system to both remove the industrial epoxy grout and to perform the single-stage ceramic tile grout sealing process has been examined through the development of a hand-held HPDL device. Also, an appraisal of the potential hazards associated with the use of the HPDL in an industrial environment and the solutions implemented to ensure that the system complies with the relevant safety standards have been thoroughly investigated and incorporated into the design of the hand-held HPDL device.

An examination of the effects of different process gasses (compressed air, $\mathrm{Ar}, \mathrm{N}_{2}$, and $\mathrm{O}_{2}$ ) was carried out for the epoxy grout removal. The study revealed that the optimum performance was achieved when employing an $\mathrm{O}_{2}$ process gas, with the amount of removal being up to twice as much as that with the other three gases. Such an occurrence is believed to be due to the fact that, of the four gases used, $\mathrm{O}_{2}$ is the most reactive. A minimum power density of approximately $300 \mathrm{~W} / \mathrm{cm}^{2}$ was found to exist. Below this value, removal did not take place regardless of the beam traverse speed. Furthermore, the minimum interaction time, below which there is no removal of epoxy grout, was found to be approximately $0.5 \mathrm{~s}$. The maximum theoretical removal rate that may be achievable using the HPDL was calculated as being $65.98 \mathrm{~mm}^{2} / \mathrm{s}$ for a circular $2 \mathrm{~mm}$ diameter beam with power density of $2.8 \mathrm{~kW} / \mathrm{cm}^{2}$ and a traverse speed of $42 \mathrm{~mm} / \mathrm{s}$.

A microstructural analysis of the HPDL removed epoxy grout revealed significant differences in the epoxy grout surface structure before and after the HPDL treatment. The surface of the HPDL-treated samples exhibited a collection of grouped particles with pores and gaps, whereas the untreated samples displayed a continuous mono-structured plane surface. The generated debris generally remained in its original position along the laser track in a single piece. The colour of the debris ranged from white to dark grey. This was brought about by the degree of oxidation taking place during HPDL interaction with the material. Both an EDX and an XRD analysis indicated changes in the chemical composition of the epoxy grout after the HPDL treatment. In particular, $\mathrm{CaO}$ was found only in the HPDL treated material. This was deemed to be the product of the decomposition of $\mathrm{CaCO}_{3}$ (limestone). In addition, $\mathrm{SiO}_{2}$ that existed in the untreated epoxy grout was not detected after HPDL interaction. It is believed that the failure to detect any trace of $\mathrm{SiO}_{2}$ in the epoxy grout after HPDL interaction is due to the compound vitrifying. A sequence thermal history for the epoxy grout 
was identified by means of a TG-DTA, thereby allowed the prediction of the reactions that occur in the epoxy grout due to HPDL interaction.

In addition, the characteristics of the single-stage ceramic tile grout sealing were examined. The single-stage ceramic tile grout sealing process yielded crack and porosity free seals which were produced in normal atmospheric conditions. Tiles were successfully sealed with power densities as low as $550 \mathrm{~W} / \mathrm{cm}^{2}$ and at rates of up to $420 \mathrm{~mm} / \mathrm{min}$. In terms of mechanical, physical and chemical characteristics, the single-stage ceramic tile grout was found to be far superior to the conventional epoxy tile grout and, in many instances, matched and occasionally surpassed that of the ceramic tiles themselves.

Bonding of the enamel to the crushed ceramic tile mix was identified as being mainly due to van der Waals forces (dispersion forces) and, on a very small scale, slight microstructural changes occurring at the interface between the crushed ceramic tile mix and the molten enamel resulting in some of the crushed ceramic tile mix material dissolving into the glaze. Optical inspection and water permeability tests revealed that a complete bond was achieved between the enamel glaze and the crushed ceramic tile mix, as well as between the enamel glaze and the vitrified surface of the ceramic tiles themselves.

\section{ACKNOWLEDGEMENTS}

The authors would like to express their gratitude to the EPSRC: Process Engineering Group (Grant No. GR/M46068) for their financial support of this work. The authors are also grateful to BNFL, Diomed Ltd., Ferro Group (UK) Ltd. and Ove Arrup \& Partners for their technical assistance.

\section{REFERENCES}

1. I. J. Spalding, in Proceedings of Applied Laser Tooling, October 1987 (ASME, New York, 1987), pp. 81-94.

2. J. Powell, I. A. Menzies, P.F. Scheyvaerts and W. M. Steen, " $\mathrm{CO}_{2}$ Laser Cutting of Non-metallic Materials" in Lasers in Manufacturing (eds. J. Powell \& I. A. Menzies, IFS Publications, Bedford, UK, 1987) pp.69-82.

3. L. Li, J. Lawrence and J. T. Spencer, in Proceedings of Europto '97, June 1997 (SPIE, Bellingham, WA, 1997), Vol 3097, pp.600-611.

4. M. Kumer, A. K. Biawas, K. Sriniwas and A. K. Nath, in Proceedings of SPIE: Laser Technologies in Industries (SPIE, Bellingham, WA, 1995), Vol 2374,pp. 34-39.

5. M. Pires, A. Ferreira, M. Ribeiro, R. Teixeira and C Rodrigues, in Proceedings of SPIE: Laser Technologies in Industries, May 1998 (SPIE, Bellingham, WA, 1998), Vol 952, pp. 622- 625. 
6. K. Sugita, M. Mori and T. Fujioka, Concrete Eng. 24, 13 (1986).

7. H. Yoshizawa, S. Wignarajah, H. Saito, Trans. Japan Welding Soc. 20, 31-36 (1989).

8. L. Li, P.J. Modern, W.M. Steen, "Laser Fixing and Sealing of Radioactive Contamination on Concrete Surfaces" Proceedings of LAMP '92, June 1992 (High Temperature Society of Japan, Osaka), pp 843-848.

9. L. Li, W.M. Steen, P.J. Modern, in Proceedings of ISLOE '93, (National University of Singapore, Singapore, 1994), pp 25-30.

10. L. Li, W.M. Steen, P.J. Modern, J.T. Spencer, in Proceedings of RECOD '94 (SPIE, Bellingham, 1994), pp 24-28.

11. L. Li, W.M. Steen, P.J. Modern, J.T. Spencer, Proceedings of EUROPTO '94: Laser Materials Processing and Machining (SPIE, Bellingham, WA, 1994), pp 84-95.

12. K.J. Blair: PhD Thesis, University of Liverpool (1996).

13. K. Sugimoto, S. Wignarajah, K. Nagasi and S. Yasu, in Proceedings of ICALEO '90, November 1990 (Laser Institute of America, Orlando, FL, 1991), pp 302-312.

14. S. Wignarajah, K. Sugimoto, K. Nagai, in Proceedings of ICALEO '92, October 1992 (Laser Institute of America, Orlando, FL, 1993), pp 383-393.

15. T.I. Borodina, G.E. Valyano, N.I. Ibragimov, E.P. Pakhomov, A.I. Romanov, L.G. Smirnova, P.K. Khabibulaev, J. Phys. and Chem. of Mater. Treatment, 25, 541-546 (1995).

16. J. Lawrence and L. Li, in Proceedings of ICALEO '99: Laser Materials Processing, October 1999 (Laser Institute of America, Orlando, FL, 2000). Vol 87B pp.108-117.

17. J. Lawrence and L. Li, Mater. Sci. Eng. A, 284, 93-102 (2000).

18. J. Lawrence and L. Li, Mater. Sci. Eng. A, 287, 25-29 (2000).

19. J. Lawrence and L. Li, J. Laser Apps. 12, 116-125 (2000).

20. G. D. Taylor. Construction Materials (Longman Scientific \& Technical, London, 1991).

21. J. Lawrence, L. Li and J. T. Spencer, Optics Laser Tech. 30, 205-214 (1998).

22. J. Lawrence, L. Li and J. T. Spencer, Optics Laser Tech. 30, 215-223 (1998).

23. J. Lawrence, PhD Thesis, UMIST, 1999.

24. M. I. Cooper, D. C. Emmony and J. Larson, J. Photographic Sci. 40, $55-57$ (1992).

25. M. I. Cooper, D. C. Emmony and J. Larson, Optics Laser Tech. 27, 69-73 (1995).

26. L. Lazzarini and J. F. Asmus, Bull. AIC, 13, 13-46 (1973). 
27. J. F. Asmus and M. J. Zetler, Lithoclastia, 1, 23-45 (1976).

28. J. F. Ready, Industrial Applications of Lasers, (Academic Press, London, 1977).

29. E. P. Johnston, G. Shannon, W. M. Steen, D. R. Jones and J. T. Spencer, in Proceedings of ICALEO '98: Laser Materials Processing, November 1998 (Laser Institute of America, Orlando, FL, 1999), Vol 85A, pp. 210-218.

30. Y. Morishita, K. Tanimoto, T. Komuro and T. Zaitsu, in Proceedings of ICONE 5: The $5^{\text {th }}$ International Conference on Nuclear Engineering, May 1997 (Springer Verlag, Berlin, 1997), pp. 2609-2608.

31. M. J. J. Schmidt, L. Li and J. T. Spencer, Optics Laser Tech. 31, 171-180 (1999).

32. D. H. Abbott and C. E. Albright, J. Laser Apps. 6, $69-75$ (1994).

33. C. Bagger, G. Broden, E. Beske and F. Olsen, Int. J. Joining Mater. 6, 68-78 (1994).

34. D. K. Y. Low, L. Li and A. G. Corfe, J. Eng. Manuf. 259, 42-55 (2000).

35. B. Bever, Encyclopaedia of Materials Science and Engineering (Prentice-Hall, New York, 1986).

36. J. A. Brydson, Plastics Materials (Butterworth-Heinemann, London, 1995).

37. P. C. Hewlett, Chemistry of Cement and Concrete (Arnold, London, 1988).

38. D. W. Richerson, Modern Ceramic Engineering (Dekker, New York, 1992).

39. G. W. Morey, The Properties of Glass (Von Nostrad Reinhold, New York, 1954).

40. J. Hlavac, The Technology of Glass and Ceramics: An Introduction (Elsevier Scientific Publishing Company, Amsterdam, 1983).

41. E. A. Simpkins, Letter to author, October 1997.

42. J. A. Pask and A. P. Tomisa, "Ceramics and Glasses", in Engineered Materials Handbook (Ed. S.J. Schneider, Metals Park: ASM International 1991), pp. 482-492.

43. V. A. Greenhut, "Adhesives and Sealants", in Engineered Materials Handbook (Ed. H.F. Brinson, ASM International, Metals Park, 1991), pp. 298-311.

44. J. G. Li, Mater. Lett. 22, 169-174 (1992).

45. V. V. Vargin, Technology of Enamels (MacLaren \& Sons, London, 1965).

46. A. Petitbon, L. Boquet and D. Delsart, Surf. Coat. Tech. 49, 57-61 (1991).

47. BS 6906: Part 3: 1989, Determination of water flow normal to the plane of a geotextile under a constant head.

48. BS 6431: Part 19: 1984, Ceramic wall and floor tiles: Method for determination of chemical resistance. Glazed tiles.

49. J. T. Spencer, Letter to author, October 1997. 
50. J. Verran, Letter to author, October 1997.

51. ASTM C597-91, Standard test method for compressive strength of chemical-resistant mortars, grouts, monolithic surfacings and polymer concretes.

52. M. J. J. Schmidt, L. Li and J. T. Spencer, J. Laser Apps. 12, 134-141 (2000).

53. J. Lawrence, L. Li and J. T. Spencer, in Proceedings of ICALEO '96: Laser Materials Processing, October 1996 (Laser Institute of America, Orlando, FL, 1997), pp. 105-114.

54. ISO 11553:1996, Safety of machinery - Laser processing machines.

55. BS EN 608251-1: Part 1: 1994, Safety of laser products. Equipment classification, requirements and users guide.

56. P. Schreiber, M. Dahmen, M. Alunovic and E. Kreutz, J. Laser Apps. 10, 181-185 (1998).

57. M. Alunovic, G. Backes, E. Kreutz, D. Scheller and P. Schreiber, Laser Praxis, 32, 96-104 (1996). 


\section{List of Figs.}

Fig. 1. Relationship between epoxy grout removal rate and HPDL power density for compressed air, $\mathrm{Ar}, \mathrm{N}_{2}$ and $\mathrm{O}_{2}$ process gases.

Fig. 2. Relationship between epoxy grout removal rate and traverse speed for compressed air, $\mathrm{Ar}, \mathrm{N}_{2}$ and $\mathrm{O}_{2}$ process gases.

Fig. 3. Schematic illustration of the operating window for the HPDL removal of epoxy grout.

Fig. 4. Typical SEM surface images of the (a) untreated and (b) HPDL treated epoxy grout.

Fig. 5. XRD analysis of the (a) untreated and (b) HPDL treated epoxy grout $\left\{\bullet \mathrm{CaCO}_{3}, \bullet \mathrm{CaO}\right.$, $\left.* \mathrm{CaMg}\left(\mathrm{CO}_{3}\right)_{2},+\mathrm{SiO}_{2}\right\}$.

Fig. 6. TG-DTA results for the epoxy grout.

Fig. 7. Schematic representation of operating window for the single-stage ceramic tile grout sealing process.

Fig. 8. Typical optical surface view of the glazed enamel surface of the single-stage ceramic tile grout $\left(2 \mathrm{~kW} / \mathrm{cm}^{2}\right.$ and $\left.240 \mathrm{~mm} / \mathrm{min}\right)$.

Fig. 9. Relationship between the single-stage ceramic tile grout HPDL interaction depth and laser power density.

Fig. 10. Relationship between the single-stage ceramic tile grout HPDL interaction depth and traverse speed.

Fig. 11. Wireframe view of the hand-held HPDL-based epoxy grout removal and single-stage ceramic tile grout sealing system. 
Fig. 1

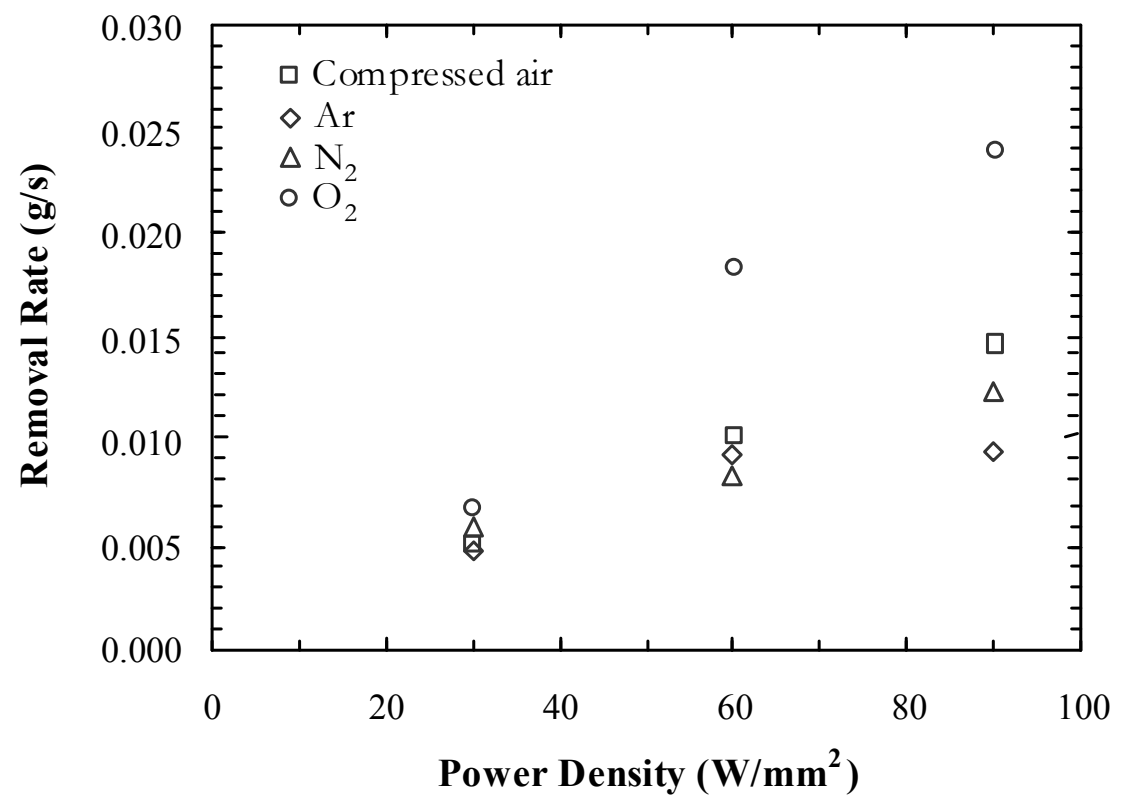


Fig. 2

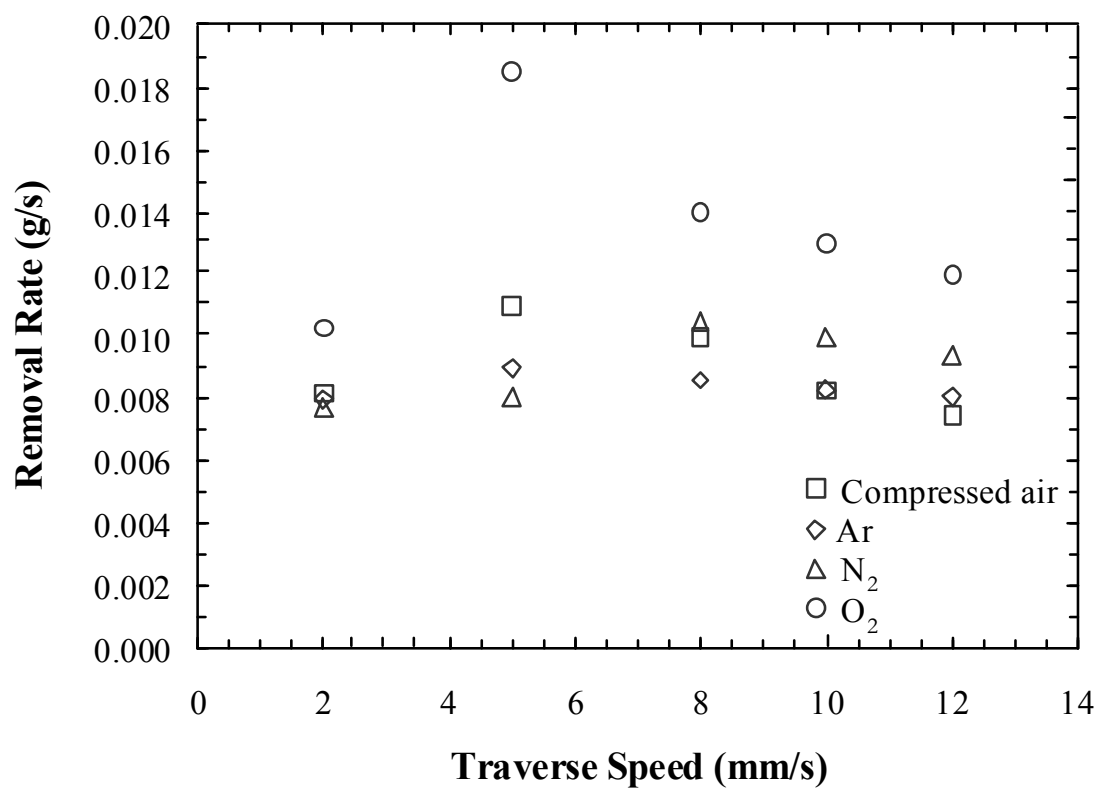


Fig. 3

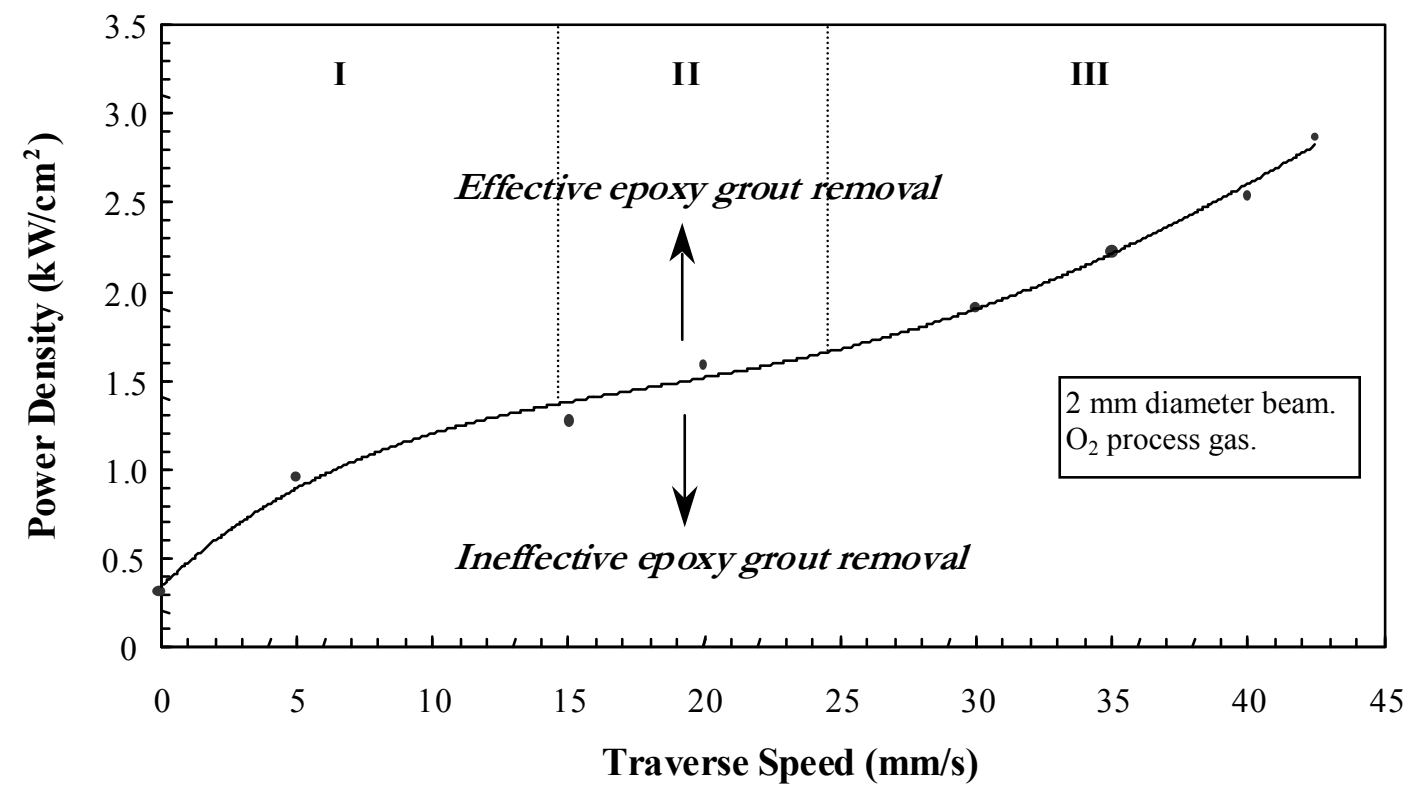


Fig. 4

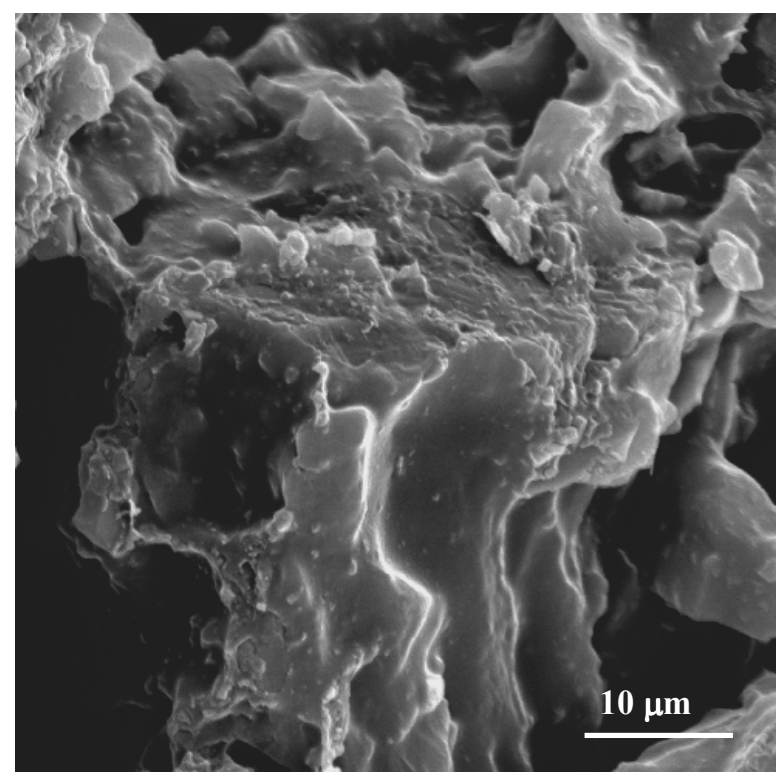

(a)

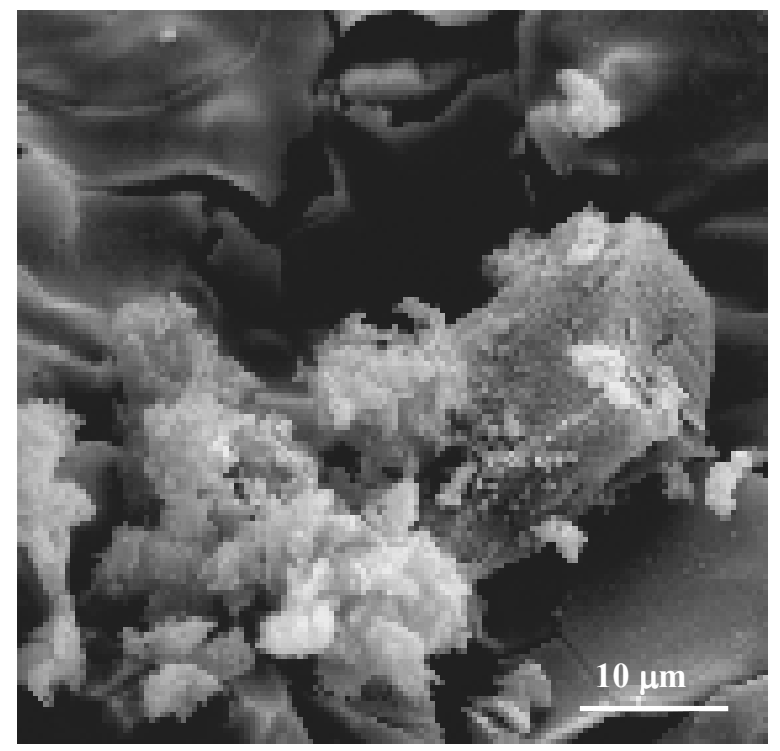

(b) 
Fig. 5

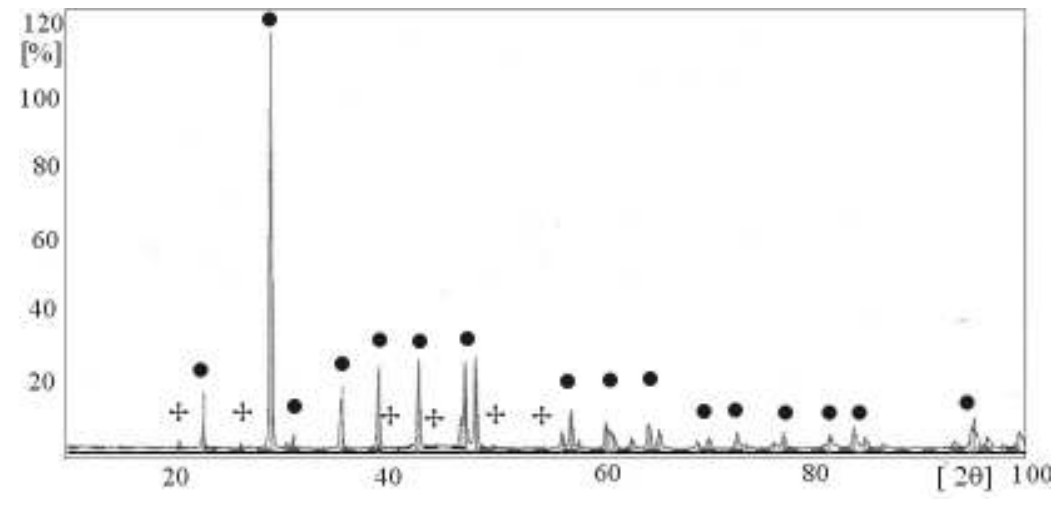

(a)

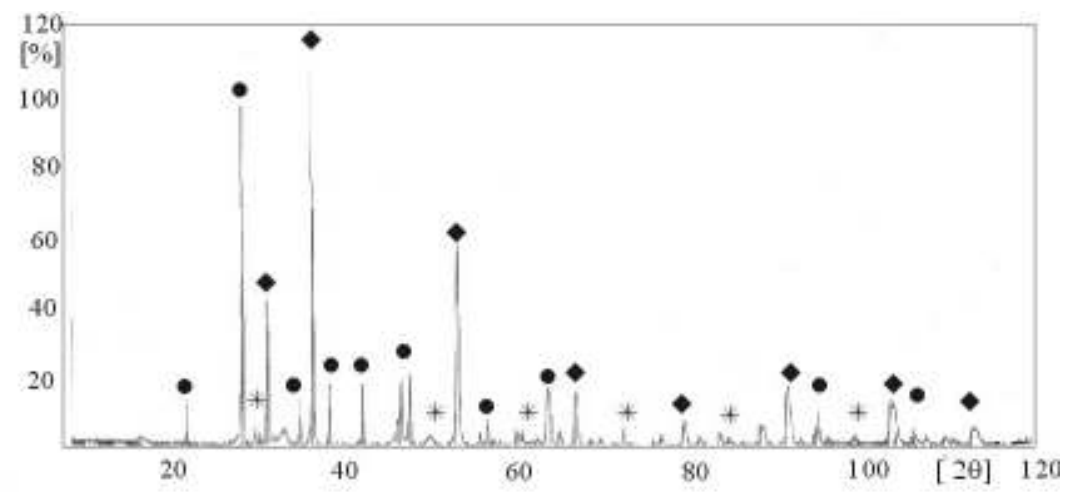

(b) 
Fig. 6

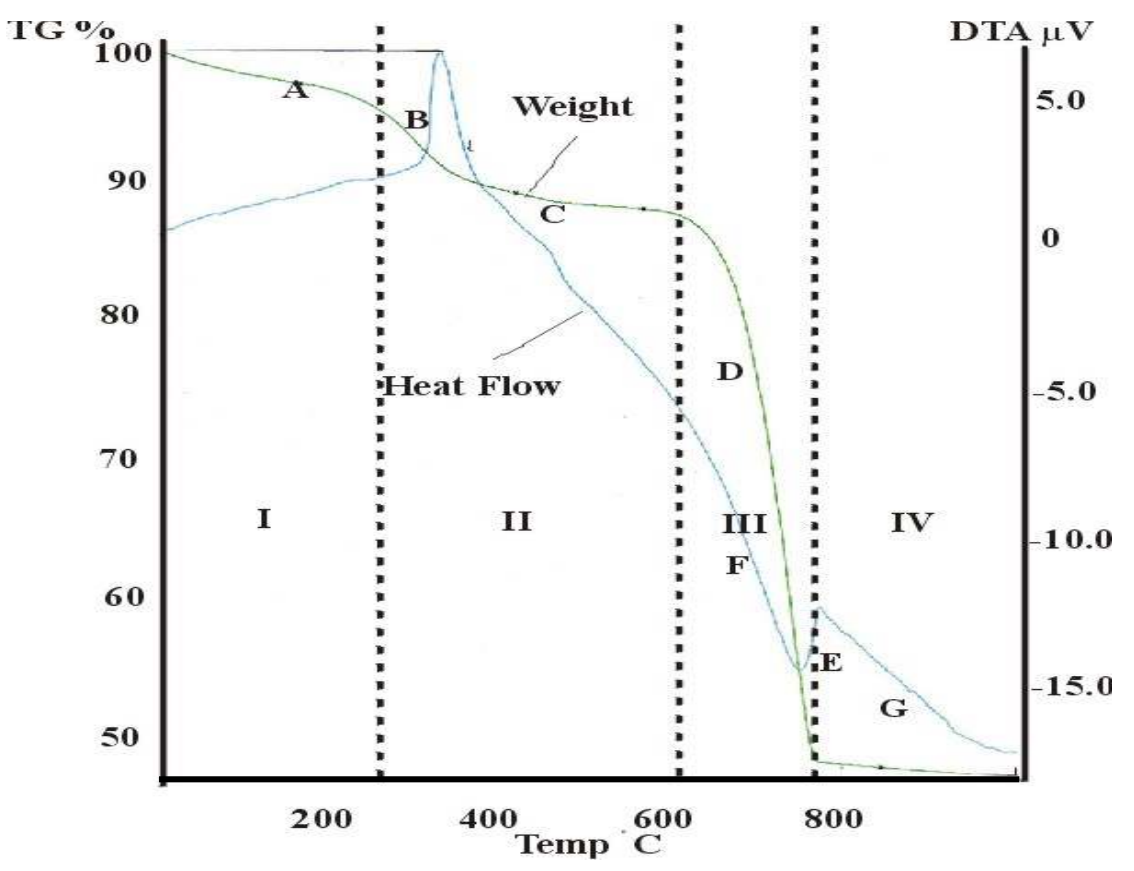


Fig. 7

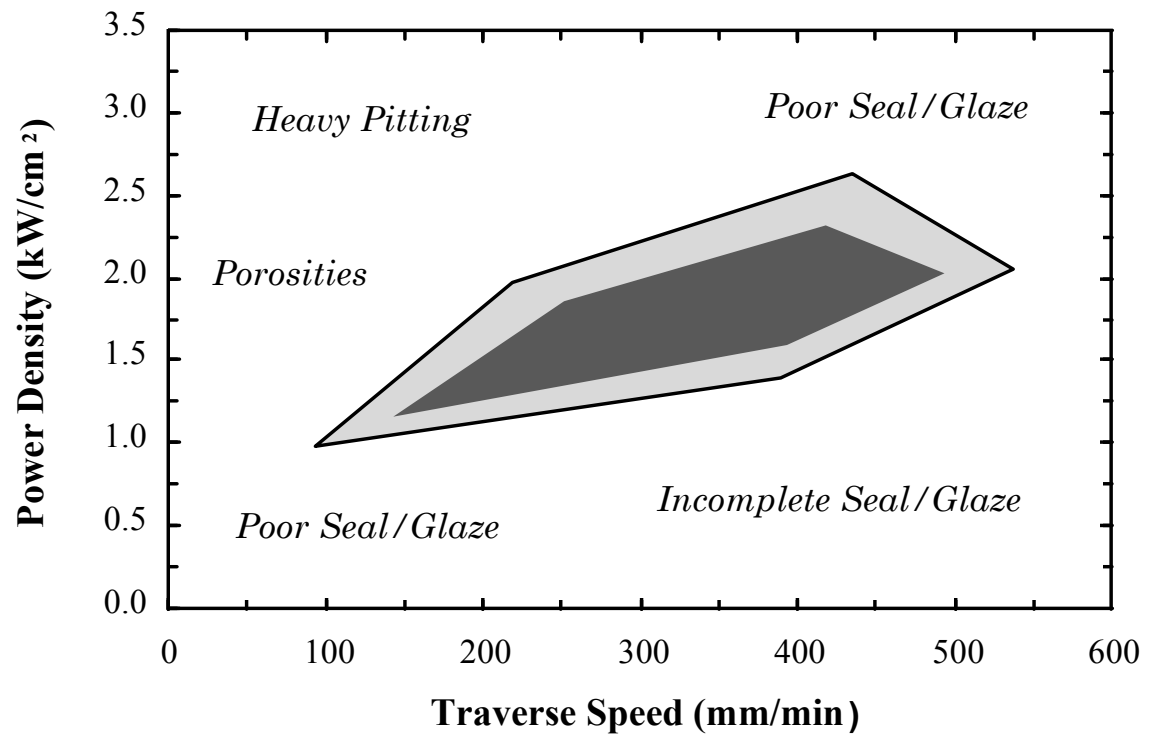

$\bigcirc$ Good Seal Quality

$\bigcirc$ Reasonable Seal Quality 
Fig. 8

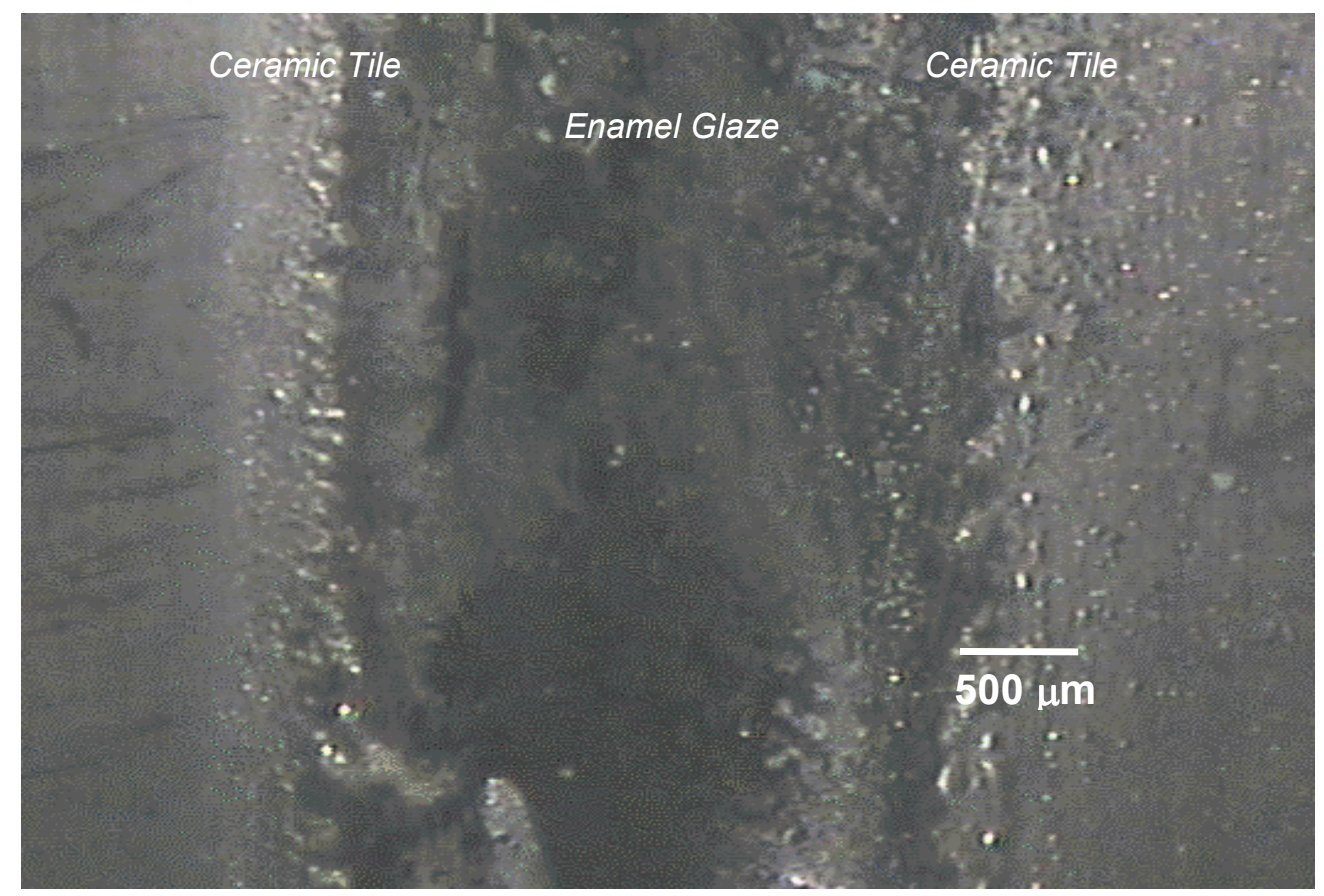


Fig. 9

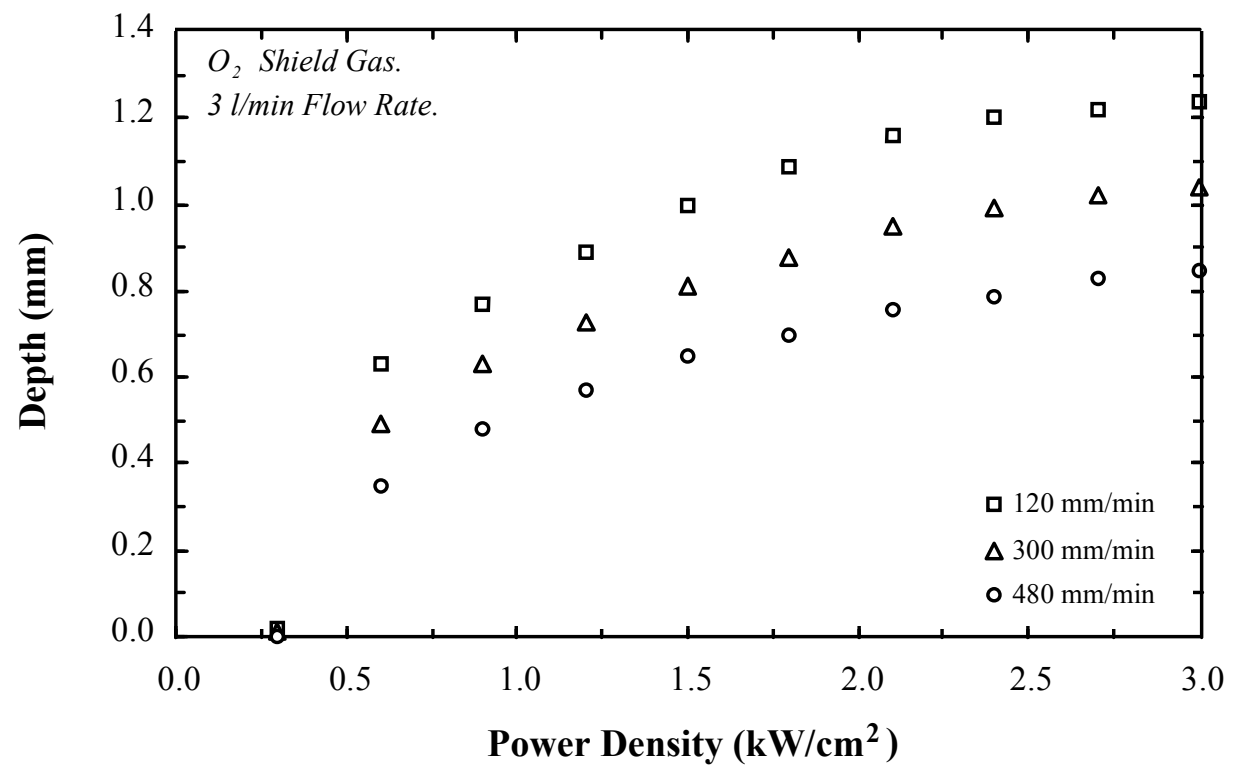


Fig. 10

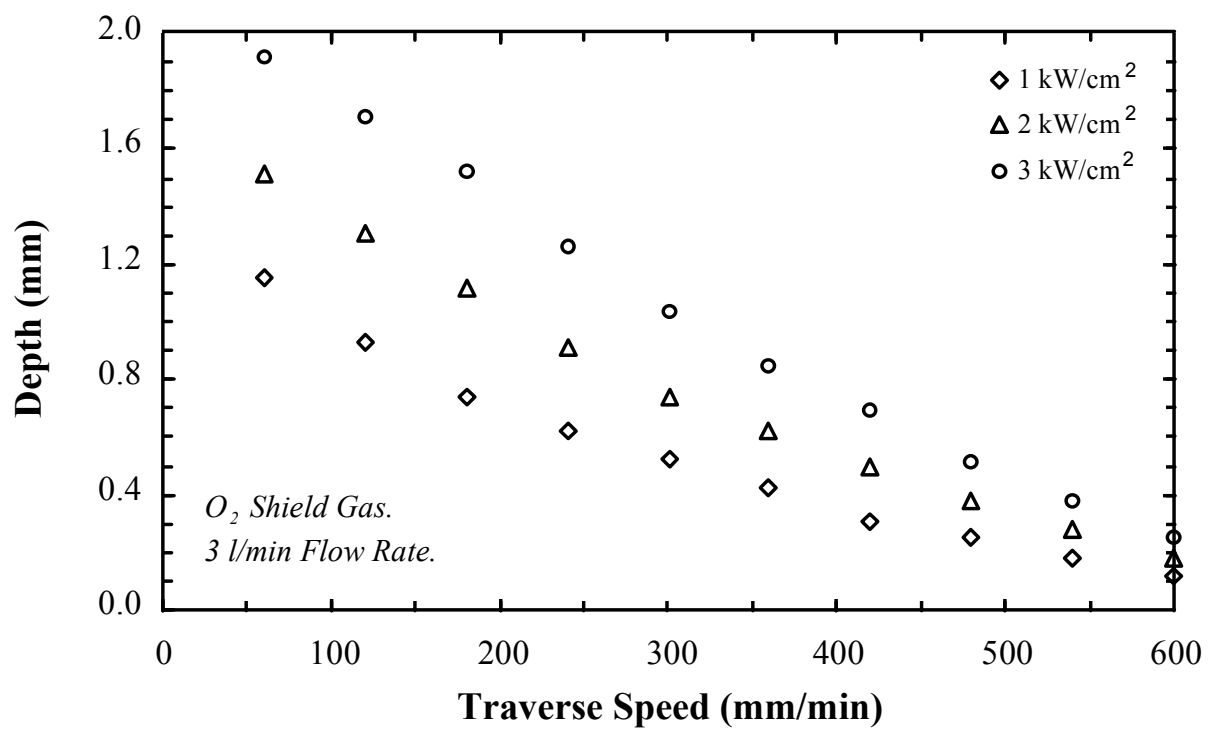


Fig. 11

Fibre optic beam delivery cable

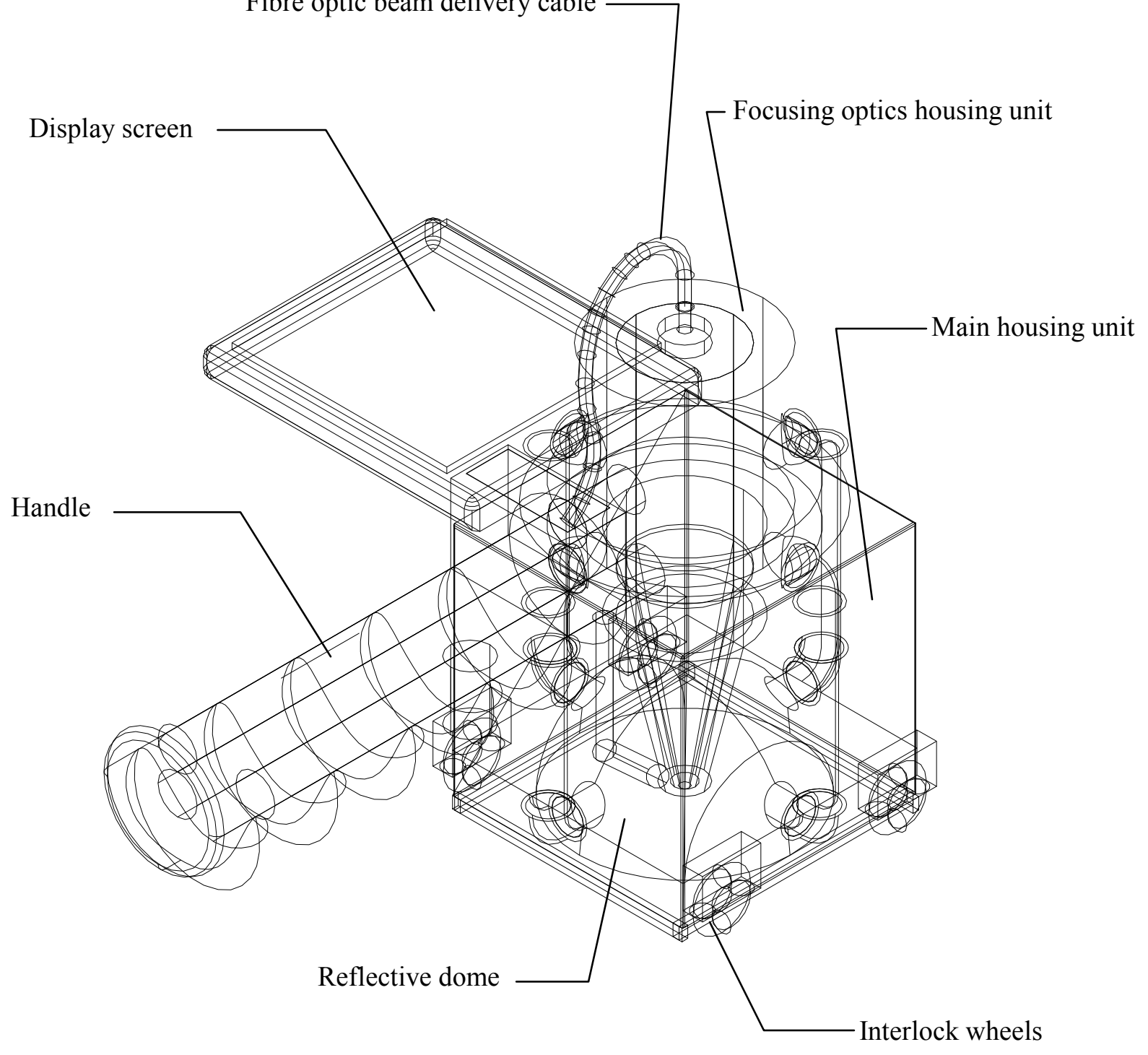




\section{List of Tables}

Table 1. Surface roughness (Ra) measurements for an epoxy tile grout, the vitrified surface of a ceramic tile and HPDL generated enamel glaze.

Table 2. Wear rate details and the nominal life increase of the HPDL generated enamel glaze over epoxy tile grout in various corrosive environments.

Table 3. MPE values for HPDL radiation for an exposure time of $10 \mathrm{~s}$. 
Table 1.

\begin{tabular}{lcc}
\hline \multicolumn{1}{c}{ Surface } & \multicolumn{2}{c}{ Surface Roughness (Ra) } \\
& Range & Ave. Roughness \\
\hline Epoxy tile grout & $2.36-5.72 \mu \mathrm{m}$ & $3.83 \mu \mathrm{m}$ \\
Vitrified ceramic tile & $0.06 \mu \mathrm{m}$ & $0.06 \mu \mathrm{m}$ \\
HPDL generated enamel glaze & $0.08-0.17 \mu \mathrm{m}$ & $0.12 \mu \mathrm{m}$ \\
\hline
\end{tabular}


Table 2.

\begin{tabular}{ccccccc}
\hline & & & \multicolumn{2}{c}{ Wear Rate $\left(\mathbf{m g} / \mathbf{c m}^{2} / \mathbf{h}\right)$} \\
\cline { 5 - 7 } & Density & Thickness & Unexposed & Detergent & NaOH & HNO $_{3}$ \\
\hline Epoxy tile grout & $2220\left(\mathrm{~kg} / \mathrm{m}^{3}\right)$ & $2000(\mu \mathrm{m})$ & 12.1 & 51.9 & 91.9 & 123.3 \\
Enamel glaze & $2650\left(\mathrm{~kg} / \mathrm{m}^{3}\right)$ & $500(\mu \mathrm{m})$ & 0.9 & 0.9 & 0.9 & 0.9 \\
\hline & Increase in Wear Life* & $\mathbf{4 . 0}$ & $\mathbf{1 7 . 5}$ & $\mathbf{3 1 . 3}$ & $\mathbf{4 2 . 0}$ \\
\hline
\end{tabular}

$$
{ }^{*} \text { Increase in Wear Life }=\frac{\text { Enamel glaze wear life }}{\text { Epoxy tile grout wear life }}
$$

where,

$$
\text { Wear Life }=\frac{\text { Density } . \text { Thickness }\left(\mathrm{mg} \cdot \mathrm{cm} / \mathrm{cm}^{3}\right)}{\text { Wear Rate }\left(\mathrm{mg} / \mathrm{cm}^{2} / \mathrm{h}\right)}
$$


Table 3

\begin{tabular}{|c|c|c|c|c|c|c|c|c|c|}
\hline \multirow{3}{*}{ Type of Exposure } & \multicolumn{3}{|c|}{ MPE Value } & \multicolumn{3}{|c|}{ MPE Equivalent Fluence } & \multicolumn{3}{|c|}{ MPE Equivalent Irradiance } \\
\hline & \multicolumn{3}{|c|}{$\left(\mathrm{J} / \mathrm{m}^{2}\right)$} & \multicolumn{3}{|c|}{$\left(\mathrm{J} / \mathrm{m}^{2}\right)$} & \multicolumn{3}{|c|}{$\left(\mathrm{W} / \mathrm{cm}^{2}\right)$} \\
\hline & $10 \mathrm{~s}$ & $1 \mathrm{~s}$ & $10^{-3} \mathrm{~s}$ & $10 \mathrm{~s}$ & $1 \mathrm{~s}$ & $10^{-3} \mathrm{~s}$ & $10 \mathrm{~s}$ & $1 \mathrm{~s}$ & $10^{-3} \mathrm{~s}$ \\
\hline Ocular Exposure & 167.9 & 25.8 & 0.09 & 0.016 & 0.002 & $9 \times 10^{6}$ & 0.0016 & 0.002 & 0.009 \\
\hline Skin Exposure & 32451 & 18299 & 3295 & 3.245 & 1.824 & 0.324 & 0.324 & 1.824 & 324.5 \\
\hline
\end{tabular}

